\title{
EDITORIAL
}

\section{UNSAFE ABORTION AND MATERNAL MORTALITY: IS AFRICA PREPARED TO FACE THE REALITY?}

Sub-Saharan Africa has, by far, the highest maternal mortality ratio today. It is estimated that the risk of dying from pregnancy-related cause for a girl born in Africa today is as high as 1:8, a thousand times higher than in the developed world(1). Safe motherhood is universaally accepted as imperative by all governments and it should ensure that all women receive the care they need to be safe and healthy throughout pregnancy and childbirth. It is generally assumed that safe motherhood ends with healthy mother and baby. But not all pregnancies are wanted and not all of them end up with a baby. Comprehensive safe motherhood strategies should therefore include all interventions necessary to prevent the death or illness of a pregnant woman - whether the pregnancy is wanted or not(2).

Of the estimated 200 million pregnancies around the world each year, approximately one third are unwanted(3). Unwanted pregnancies contribute to poor maternal health outcomes in two ways: First, many pregnancies are unwanted because they threaten the woman's health or well-being; she may have an existing health problem, or lack the support and resources she needs to have a healthy pregnancy and raise a healthy child. Second, where women do not have access to safe abortion services, many unwanted pregnancies are terminated using unsafe procedures that can lead to the woman's death or disability. Both of these two factors are common place in Africa(3-5).

Unsafe abortion is defined as a procedure for terminating an unwanted pregnancy either by persons lacking the necessary skills or in an environment lacking the minimal medical standards or both(6). Unsafe abortion is one of the five major causes of maternal mortality and accounts for $13 \%$ of maternal deaths globally but up to $50 \%$ in sub-Saharan Africa(4,6). Of the 46 million abortions that take place in a year, 20 million are considered unsafe, resulting in roughly 70,000 deaths and hundreds of thousands of disabilities. Almost all (95\%) unsafe abortions occur in developing countries because the developed world has made it possible for women to easily prevent unwanted pregnancy by using contraceptives and having access to safe legal termination when needed $(3,7)$.

When carried out according to appropriate clinical guidelines and with trained personnel, abortion has the lowest physical risks for women of any significant medical intervention(8). However, for most women in the developing world, abortions are often conducted in unsanitary conditions by untrained personnel. It is estimated that between 10 and $50 \%$ of women who undergo unsafe abortions need medical care for complications. These complications include infection, haemorrhage and injury to internal organs, and can lead to long-term health problems such as chronic pain, pelvic inflammatory disease, and infertility $(3,4,6)$.

In addition to the health impact of unsafe abortion, there are also significant financial costs(9). Costs for women and their families include fees for services, medicine and supplies, transportation, and opportunity costs from inhability to work. Unsafe abortion also places a huge burden on health care systems, especially in sub-Saharan Africa, women with incomplete abortion account for half of gynaecological admissions at hospitals. Their treatment has traditionally required several days of hospital stay, occupying significant staff time, antibiotics, anaesthesia, intravenous fluids and blood transfusion. Some patients with severe complications end up in intensive care units or may require renal dialysis(4). Previous attempts to calculate the true cost of unsafe abortions have always come short of the real estimates, especially in circumstances where the procedure is clandestinely performed and the expenditure prior to hospitalisation is hidden.

Two papers attempt to address this important subject in this issue of the journal $(10,11)$. They should be read by everyone interested in public health in Africa. It is important that readers are reminded of two things. First, unsafe abortion is an equity issue for, irrespective of the state of the law in any country, only poor women die from unsafe abortion. The rich will always buy safe termination of pregnancy. Second, policy decisions on abortion are rarely based on reason or data. Advocates for restrictive abortion laws are not driven by ignorance but by unbending belief in their moral position that will not be changed by data nor understanding of the circumstances that lead millions of women to risk their lives in the quest to terminate a pregnancy, despite the laws(5).

Today, sub-Sahara Africa is at crossroads. For African governments that are faced with the challenges of the Millenium Development Goal of reducing maternal mortality by $75 \%$ by 2015 , there needs to be a clear recognition that this will not be possible without addressing unsafe abortion which results in half of maternal deaths. And unsafe abortion cannot be reduced unless an enabling legal and clinical environment is created that puts the woman's interest first and empowers skilled providers to save lives of all women (not just the rich), is created. As has been demonstrated in many countries, laws and policies affect both the quality and type of care available to women. It is important also for African governments to recommit to funding family planning programmes that serve individual preferences by providing access to a broad range of contraceptive options, and can help prevent unwanted pregnancies. Where quality family programmes are in place, the use 
of effective contraceptive methods rises; fewer unwanted pregnancies occur and recourse to abortion declines.

For African health providers, they need to know that they have a professional responsibility to speak truthfully and unambiguously on this issue. They cannot afford to sit on the fence in the face of the glaring inequity that restricted abortion services create in their communities. In almost all countries (98\%) around the world, abortion is legally permitted to save a woman's life, while close to two-thirds of countries allow abortion to preserve a woman's physical health (63 percent) or mental health (62 percent). However, safe abortion services are often not available to the full extent permitted by law, in part due to lack of awareness of the legal status in communities and indifference among health providers. Anecdotal reports that doctors benefit financially from the illegal status of abortion in their countries (hence their reluctance to speak for change) are on the increase and cannot be taken lightly.

Unsafe abortion is the most easily preventable and treatable cause of maternal death and disability. Effectively, addressing unsafe abortion requires a comprehensive approach to women's health and rights, and involvement of a wide range of stakeholders, including government, non-governmental organisations (NGOs), health providers, and communities, as well as international agencies and donors. But, as the saying goes, charity begins at home. This is 2004 . Africa must now face the reality and address the following hard questions:

Can we meet the Millenium of Development Goals without addressing the issue of unsafe abortion? Can we comprehensively address unsafe abortion without reviewing the laws? What is the justification for keeping intact laws of colonial inheritance that have been discarded, on the basis of good reasons, by the colonialists themselves.

K. O. Rogo MD, PhD.

Lead Health Sector Specialist

Population and Reproductive Health

The World Bank

1818 H Street, NW

Washignton DC 20433

USA

Disclaimer: Opinions in this paper are the author's and should not be attributed to the World Bank.

\section{REFERENCES}

1. The Alan Guttmacher Institute. Sharing Responsibility: Women, Society, Abortion Worldwide. New York. 1999.

2. Rahman, A., Katzin, L., Henshaw, S.K. A global review of laws on induced abortion. 1985-1997. Int. Fam. Plann Persp. 1998; 24:56.

3. Hord, C.E., Baird, T.L., Billings, D.L. Advancing the role of midlevel providers in abortion and post-abortion care: a global review and key future actions. Issues in Abortion Care No. 6. Carrboro, NC: Ipas, 1999.

4. Johnson, B.R., Ndlovu, S., Farr, L.S. and Chipato, T. Reducing Unplanned Pregnancy and Abortion in Zimbabwe through Post Abortion Contraception. Studies in Family Planning. 2002; 33(2).

5. Kinoti, S. Gaffikin, L. and Benson, J. How research can affect policy and program advocacy. 2004; 81

6. McKay, H.E., Rogo, K.O. and Dixon, D.B. FIGO society survey: acceptance and use of new ethical guideline regarding induced abortion for non-medical reasons. Inter. J. Gyne. Obstet. 2001; 75:327-336

7. Mosoko, J.J., Delvaux, T., Glynn, J.R., Zekeng, L., Macauley, I. and Buve, A. Induced abortion among women attending antenatal clinics in Yaounde, Cameroon. East Afr. Med. J. 2004; 81.

8. Postabortion Care Consortium Community Task Force, "Essential elements of post abortion care: an expanded and updated model." PAC in Action no. 2 Special Supplement. September 2002.

9. Rogo, K.O. Induced abortion in sub-Saharan Africa. East Afr. Med. J. 1993; 70:386-395.

10. Rogo, K.O., Orero, S. and Oguttu, M. Preventing unsafe abortion in Western Kenya. An innovative approach through private physicians. Reproductive Health Matters, 1998; 6:77-83.

11. K. Rogo, K.O., Bohmer, L. and Ombaka, C. Community level dynamics of unsafe abortion in western Kenya and opportunities for prevention: Summary of findings and recommendations from pre-intervention research. Los Angeles, CA: Pacific Institute for Women's Health, 1999.

12. Rogo, K.O. Improving technologies to reduce abortion related morbidity and mortality. Int J. Gynecol and Obstet. 2004 (in press)

13. The Safe Motherhood Action Agenda: Priorities for the Next Decade. Report on the Safe Motherhood Technical Consultation, 13-23 October 1997, Colombo, Sri Lanka. Family Care International in collaboration with the InterAgency Group for Safe Motherhood.

14. World Health Organization. (1998) Unsafe abortion: global and regional estimates if incidence of and mortality due to unsafe abortion with a listing of available country data. Geneva, World Health Organization. (WHO/RHT/ MSM/97. 16)

15. WorldHealthOrganization. Safe Abortion: Technical and Policy Guidance for Health Systeins. Geneva. 2003. 